J. Dairy Sci. 97:3099-3109

http://dx.doi.org/10.3168/jds.2013-7823

(C) American Dairy Science Association ${ }^{\circledR}, 2014$.

\title{
Group housing of Holstein calves in a poor indoor environment increases respiratory disease but does not influence performance or leukocyte responses
}

\author{
C. J. Cobb, ${ }^{\star}$ B. S. Obeidat, ${ }^{\star} \dagger$ M. D. Sellers, ${ }^{\star}$ A. R. Pepper-Yowell, ${ }^{\star}$ and M. A. Ballou ${ }^{\star 1}$ \\ *Department of Animal and Food Sciences, Texas Tech University, Lubbock 79409 \\ †Department of Animal Production, Faculty of Agriculture, Jordan University of Science and Technology, Irbid 22110, Jordan
}

\begin{abstract}
The objective of the current study was to determine if group-housing Holstein heifer calves in indoor pens with poor ventilation and drainage influences performance, health, leukocytes, and behavioral responses compared with individually housed calves. Ninety colostrum-fed calves ( $2 \pm 1 \mathrm{~d}$ of age) were randomly assigned to 3 treatments: individually housed (G1; n $=30$ calves), 2 calves per pen ( $\mathrm{G} 2 ; \mathrm{n}=30$ calves), or 3 calves per pen (G3; $\mathrm{n}=30$ calves). The space allowance per calf was $2.5 \mathrm{~m}^{2}$ for all treatment groups. All calves were fed 747 and $1,010 \mathrm{~g} / \mathrm{d}$ of dry matter of a $28 \% \mathrm{CP}$ and $20 \%$ fat milk replacer during the first 2 wk and wk 3 to 6 , respectively. Weaning was initiated on d 46 by removing the evening feeding, and calves were completely weaned when they consumed $800 \mathrm{~g} / \mathrm{d}$ of dry matter calf starter for 2 consecutive days after d 54. Calves were randomly commingled at d 90 in groups of 5 calves per pen in outdoors pens with an attached hutch. Peripheral blood was collected during the neonatal $(3,10,21 \mathrm{~d})$, weaning $(46,48,54 \mathrm{~d})$, and commingling periods $(90,93,98 \mathrm{~d})$ and was analyzed for neutrophil oxidative burst capacity when cocultured with an Escherichia coli, neutrophil surface L-selectin protein concentration, and whole blood secretion of tumor necrosis factor- $\alpha$ when cocultured with lipopolysaccharide. Behavior of each calf was assessed using 2 independent tests: an approach response to a human subject and the response of the calf when placed in an isolated cage. Calf starter intake was greater for G2 and G3 during wk 8 and 9, and also at wk 11 for G3 compared with G1. No treatment $\times$ time interaction or treatment effect for average daily gain was observed. Additionally, no treatment $\times$ time or treatment effect was noted for any leukocyte or biochemical variable of biological significance throughout the entire study. Individually housed calves tended to have a reduced
\end{abstract}

Received December 12, 2013.

Accepted January 25, 2014.

${ }^{1}$ Corresponding author: michael.ballou@ttu.edu incidence of respiratory disease during the first $90 \mathrm{~d}$ of life. No other treatment differences for the other health outcomes were observed. Group-housed calves also relied more on calf-to-calf interactions than calf-to-human interactions, as evident by their reduced approach of the human observer and more frequent movement when placed in an isolated pen. Group housing in an environment with poor ventilation and drainage may increase the risk of respiratory disease.

Key words: calf, health, housing, respiratory

\section{INTRODUCTION}

Passage of legislation throughout the European Union (Council of the European Union, 1997) and United States (Office of the Attorney General, 2008) has demonstrated the concern of governments and the public sector to maintain natural gregarious behavior in herd animals. The incidences of infectious diseases among dairy calves are great, and recent reports indicate that $7.8 \%$ of heifer calves born alive die before weaning (NAHMS, 2007). Individually housing dairy calves during the preweaning period is a popular management strategy that can help reduce the horizontal transmission of infectious diseases (Fourichon et al., 1997; Gulliksen et al., 2009). Calves are typically moved into group pens either at weaning or within a month of weaning when the risk of morbidity and mortality are reduced (NAHMS, 2007).

Cobb et al. (2014) indicated that housing calves in groups of 3 in outdoor pens with an attached calf hutch increased postweaned calf starter intake and ADG when compared with individually housed calves. Increased intake of calf starter is commonly observed when calves are commingled (Warnick et al., 1977; Babu et al., 2004). Cobb et al. (2014) also reported that group-housed calves relied more on calf-to-calf interactions, whereas individually housed calves were more dependent on human interaction. Although increased calf starter intake and social interactions among the group-housed calves are potentially favorable outcomes, the well-being of a calf is also highly 
dependent on their health, as the risk of morbidity and mortality is great (NAHMS, 2007, 2011). Cobb et al. (2014) observed that the group-housed calves had increased neutrophil activity during the preweaning period, which indicates that those calves had more active innate leukocyte responses. The authors hypothesized that the increased neutrophil activity was related to increased microbial exposure due to the interactions among the group-housed calves.

In areas throughout the world where drastic temperature changes or cold climates are common, a large proportion of dairy calves are housed indoors (Vasseur et al., 2010). Indoor environments that do not have appropriate ventilation or drainage can have greater humidity, airborne noxious gases and dust, and bacterial growth in moist bedding, which can all have negative effects on a calf's health and well-being (Woolums et al., 2009). The objectives of the present study were to evaluate the effects of group housing calves in indoor pens with straw bedding and poor natural ventilation and drainage on the performance, health, leukocyte responses, and behavior of neonatal, weaned, and commingled Holstein dairy heifers. We hypothesized that (1) group-housed calves would have more active neutrophils and suppressed health compared with individually housed calves and (2) group-housed calves would consume more calf starter after weaning and have improved postweaned performance.

\section{MATERIALS AND METHODS}

\section{Experimental Design and Calves}

All animal procedures were reviewed and approved by the Texas Tech University Animal Care and Use Committee. The experiment was conducted from June to September 2011. The average minimum and maximum temperatures during the experimental period were 19.6 and $34.3^{\circ} \mathrm{C}$, respectively, and the average relative humidity in the barn was $74 \%$. The average outdoor wind velocity was $15.8 \mathrm{~km} / \mathrm{h}$. Ninety Holstein heifer calves (2 $\pm 1 \mathrm{~d}$ of age) were purchased from a single commercial dairy farm and transported $78 \mathrm{~km}$ to the Hilmar Cheese and Agri-Plastics Calf Research Facility at Texas Tech University (New Deal, TX) in 4 enrollment groups over a 12-d period. All calves were fed $4 \mathrm{~L}$ of colostrum at the dairy within the first $12 \mathrm{~h}$ of life. Upon enrollment in the study, a peripheral blood sample was taken and individual total serum protein was recorded using a hand-held refractometer (Atago, Bellevue WA). Total serum protein was not different among groups, and averaged $5.8 \mathrm{~g} / \mathrm{dL}$ with a range of 5.0 to $7.5 \mathrm{~g} /$ $\mathrm{dL}$. Upon arrival at the research facility, each calf was weighed, shoulder height and length from the scapula to the pins were measured, and calves were randomly assigned to either an indoor individual pen $(\mathbf{G} \mathbf{1} ; \mathrm{n}=$ 30 calves), 2 calves per pen ( $\mathbf{G} \mathbf{2} ; \mathrm{n}=30$ calves), or 3 calves per pen ( $\mathbf{G} \mathbf{3} ; \mathrm{n}=30$ calves). All calves were housed in commercial polyethylene calf pens with G1, G2, and G3 calves being housed in 1.83- $\times 1.17-\mathrm{m}$, $1.83-\times 2.34-\mathrm{m}$, and $1.83-\times 3.51-\mathrm{m}$ pens (Agri-Plastics, Tonawanda, NY), respectively. The space allowance per calf was $2.5 \mathrm{~m}^{2}$ for all treatment groups. Calves were housed in a single poor, naturally ventilated barn with openings of $3.66 \times 2.74 \mathrm{~m}$ on each side of the $30-\times$ $22-\mathrm{m}$ barn. The height of the barn averaged $6.5 \mathrm{~m}$. The treatment pens were randomly distributed throughout the barn to prevent any confounding effect of location within the barn. The straw bedding was changed once weekly in all pens because it became soiled due to the poor drainage and airflow. Soiled bedding was removed and new straw was added at approximately a 20- to 25-cm pack.

\section{Feeding and Weaning}

All calves were fed a $28 \% \mathrm{CP}$ and $20 \%$ fat milk replacer (Cow's Match, Land O'Lakes Animal Milk Products Co, Shoreview, MN; Table 1). During the first 2 wk of the study, calves were offered a total of $747 \mathrm{~g}$ of $\mathrm{DM} / \mathrm{d}$ (dissolved in $4.8 \mathrm{~L}$ of water), whereas from the third week until weaning was initiated each calf was offered 1,010 g of DM/d (dissolved in $5.7 \mathrm{~L}$ of water). All calves were fed twice daily at 0730 and $1630 \mathrm{~h}$ for the duration of the study using 3-L milk bottles. Each group-housed calf was trained to receive their milk at a specific location in the pen, and researchers prevented calves from stealing milk from each other. Voluntary milk replacer refusals were recorded approximately 15 min after each feeding. After the first week, all calves were offered ad libitum access to calf starter and water for the remainder of the study (Table 1). Calf starter was adjusted daily for approximately a $10 \%$ refusal. No roughage was offered during the study. Weaning was orchestrated by block, with 2 enrollment groups in each weaning block. Weaning was started at approximately $\mathrm{d}$ 46 by restricting intake of milk replacer to the morning feeding only, where each calf was offered $323 \mathrm{~g}$ of DM/d in $1.89 \mathrm{~L}$ of water. Calves were weaned completely when daily consumption of calf starter exceeded $800 \mathrm{~g} / \mathrm{d}, \mathrm{DM}$ basis, for 2 consecutive days after d 54 . All calves were vaccinated on d 35 and given a booster on d 56 with Vista $5 \mathrm{SQ}$ (infectious bovine rhinotracheitis; bovine virus diarrhea Types 1 and 2; parainfluenza-3 virus; and bovine respiratory syncytial virus) and Vision 7 with SPUR (Clostridium spp. chauvoei, septicum, novyi, sordelli, perfringens Types $\mathrm{C}$ and $\mathrm{D}$, and Haemophilus somnus; Merck Animal Health, Summit, NJ). 
Table 1. The formulated nutrient content of the milk replacer and the calf starter

\begin{tabular}{lcc}
\hline Nutrient & $\begin{array}{c}\text { Milk } \\
\text { replacer }\end{array}$ & $\begin{array}{c}\text { Calf } \\
\text { starter }^{1}\end{array}$ \\
\hline CP, \% & 28.0 & 20.0 \\
Ether extract, \% & 20.0 & 2.2 \\
Crude fiber, \% & 0.15 & 16.0 \\
ADF, \% & - & 18.0 \\
Calcium, \% & 1.0 & 1.0 \\
Phosphorus, \% & 0.70 & 0.50 \\
Selenium, mg/kg & - & 0.30 \\
Vitamin A, IU/kg & 44,000 & 7,700 \\
Vitamin $\mathrm{D}_{3}, \mathrm{IU} / \mathrm{kg}$ & 11,000 & - \\
Vitamin E, IU/kg & 220 & - \\
\hline
\end{tabular}

${ }^{1}$ The calf starter (Cornerstone Ampli-Calf) with monensin was fed using macro-ingredients, which included grain products, processed grain by-products, plant protein products, molasses, and roughage products (Purina Mills, Gray Summit, MO). Also, the calf starter was formulated with a proprietary blend of a yeast extract, fructooligosaccharide, anise oil, garlic oil, cassia, ethyl vanillin, and propylene glycol. The trace mineral and vitamins that used in the calf starter were mostly organic sources including zinc amino acid complex, manganese amino acid complex, copper amino acid complex, cobalt glucoheptonate, and cobalt proteinate.

On d 90, calves were randomly commingled into larger outdoor groups $(\mathrm{n}=5$ calves per pen). The outdoor group pens were a $3.05-\times 4.88-\mathrm{m}$ uncovered pen attached to a $2.26-\times 2.69-\mathrm{m}$ commercial polyethylene hutch (Agri-Plastics). During this period, calves were fed $4.1 \mathrm{~kg}$ of DM of a concentrate pellet (Ampli-Calf; Purina Mills, Gray Summit, MO) per head per day and were offered chopped alfalfa hay ad libitum. The hay and the concentrate were analyzed according to the AOAC International (1995) procedures. The chemical composition for the concentrate was 97.3, 22.4, and $22.5 \%$ DM, CP, and starch, respectively, whereas the alfalfa hay was 91.5, 16.2, 44.1, and 30.0\% DM, CP, $\mathrm{NDF}$, and ADF, respectively. The concentrate pellet was formulated with similar ingredients, micronutrients, and feed additives as the calf starter (Table 1).

\section{Health Observations}

Fecal scores were assessed twice daily according to the guidelines outlined by Larson et al. (1977). Scores were 1 = firm, well-formed (not hard); $2=$ soft, puddinglike; $3=$ runny, pancake batter; and $4=$ liquid, splatters, pulpy orange juice. All fecal scores were recorded by observing fecal matter on the ground of the pen or on the tail and hind quarters of the calf. All fecal score data were collected by 1 independent trained observer. Any calf with a fecal score $\geq 3$ received acidified oral electrolytes added to their milk replacer at each feeding (BlueLite, TechMix, Stewart, MN). A calf with scours was defined as having a fecal score $\geq 3$ for 2 consecutive days. Severely ill calves, with no suckle reflex and a decreased response to external stimuli, during the first 2 wk of life were treated with florfenicol-flunixin meglumine (Resflor Gold; Merck Animal Health) and given oral electrolytes in $2 \mathrm{~L}$ of milk replacer using an esophageal feeder. Calves that had respiratory disease, nasal discharge, cough, and a rectal temperature $\geq 39.5^{\circ} \mathrm{C}$ were treated with Resflor Gold.

\section{Sampling and Blood Collection}

Calves were weighed individually on a large veterinary animal platform scale (Arlyn Scales, East Rockaway, NY) at arrival and at d 7,21, 54, 68, 90, 113, 133, and 160 of the study. Bone length from the hoof to the scapula (height) and scapula to the pin (length) were measured to the nearest $0.2 \mathrm{~cm}$ with a tailor's tape on the same day BW was recorded. Nine milliliters of peripheral blood was collected from the jugular vein at d 3, 10, 21, 46, 48, 54, 90, 93, and 98 into 3- and 6-mL evacuated tubes (Vacutainer, Becton Dickinson, Rutherford, NJ) containing $\mathrm{K}_{2} \mathrm{EDTA}$ and heparin, respectively. The $\mathrm{K}_{2}$ EDTA tube was placed immediately on ice and the heparin tube was placed in an ice chest without ice (Sellers et al., 2013). Plasma from the heparinized Vacutainer was obtained after centrifugation at $1,200 \times g$ for 15 min and stored at $-40^{\circ} \mathrm{C}$ until subsequent analyses. Plasma glucose and urea nitrogen concentrations were analyzed using commercially available enzymatic, colorimetric kits (Stanbio Laboratory, Boerne, TX). Plasma haptoglobin concentrations were determined by measuring haptoglobin or hemoglobin complex by the estimation of differences in peroxidase activity (Hulbert et al., 2011). All colorimetric data were measured on a SpectraMax 340PC (Molecular Devices, Sunnyvale, CA). Control serum (Randox Laboratories, Oceanside, CA) was used to calculate the interassay $\mathrm{CV}$ of 5.4 and $6.4 \%$ for plasma glucose and urea nitrogen, respectively. Intraassay CV were 5.1 and $6.8 \%$ for plasma glucose and urea nitrogen, respectively. The intra- and interassay CV for plasma haptoglobin were 1.4 and $3.4 \%$, respectively.

\section{Ex Vivo Leukocyte Analyses}

On d 3, 10, 21, 46, 48, 54, 90, 93, and 98, whole blood from the heparinized Vacutainer was diluted 1:4 in RPMI medium at a final concentration of $1 \%$ antibiotic-antimycotic (Invitrogen Life Technologies, Grand Island, NY) and $1 \mu \mathrm{g} / \mathrm{mL}$ of LPS (Escherichia coli 0111:B4; Sigma; St. Louis, MO). Cell suspensions were incubated for $24 \mathrm{~h}$ at $38^{\circ} \mathrm{C}$ in a humidified $5 \%$ $\mathrm{CO}_{2}$ incubator. The supernatant was removed after the cell suspension was centrifuged for $15 \mathrm{~min}$ at 1,200 $\times g$ and stored at $-40^{\circ} \mathrm{C}$ until analyzed for concentrations 
of tumor necrosis factor- $\alpha$ by a commercially available bovine-specific ELISA kit (R\&D Systems, Minneapolis, $\mathrm{MN})$.

The oxidative burst ( $\mathbf{O B}$ ) capacities of whole blood neutrophils in response to an enteropathogenic $E$. coli were analyzed as described by Hulbert et al. (2011). Briefly, $200 \mu \mathrm{L}$ of whole blood from the heparinized Vacutainer was incubated in an ice bath for $15 \mathrm{~min}$. Forty microliters of a $100 \mu M$ working concentration of dihydrorhodamine (Invitrogen Life Technologies) and the E. coli were added to each sample, vortexed thoroughly, and then placed in a $38.5^{\circ} \mathrm{C}$ water bath and incubated for $10 \mathrm{~min}$. Immediately after the 10-min incubation, all samples were placed in an ice bath for 5 min to stop the reaction at a constant rate. Erythrocytes were hypotonically lysed and washed, and the leukocytes were analyzed using a Cell Lab Quanta SC flow cytometer (Beckman Coulter, Fullerton, CA). Using flow cytometer analysis software (QuantaSC MPL, Beckman Coulter), neutrophils were gated on the scatterplot of electric volume $\times$ side scatter. The percentage of neutrophils that were positive for OB were gated, as neutrophils that had a greater fluorescence intensity than neutrophils from control cultures that remained on ice during the incubation period. Data are reported as both the percentage of neutrophils positive for $\mathrm{OB}$ as well as the geometric mean fluorescence intensity of the positive neutrophil population.

Two hundred microliters of whole blood from the EDTA Vacutainer was incubated at a final dilution of $5 \mu \mathrm{g} / \mathrm{mL}$ of antibovine CD62L (monoclonal antibody IgG1-isotype made in mouse; VMRD, Pullman, WA) for $1 \mathrm{~h}$ in an ice bath. Erythrocytes were hypotonically lysed and then rinsed once. The leukocyte pellet was resuspended in fluorescein-labeled secondary antibody at a 1:400 dilution [F(ab')2 antimouse IgG:FITC; AbD Serotec, Raleigh, NC]. Samples were incubated on ice for an additional $1 \mathrm{~h}$. Samples were then washed twice using $1 \times$ PBS and then analyzed by single-color flow cytometry. Using the flow cytometer analysis software, neutrophils were gated on the scatterplot of electric volume $\times$ side scatter. The total geometric mean fluorescence intensity for L-selectin was analyzed (Hulbert et al., 2011).

\section{Behavioral Observations}

Behavioral scoring was measured in 2 independent tests. The first test measured the approach response of each calf to a human subject. Scores were given as an observer entered the pen with the calf on d 10, 21, 46, 48, 54, and 90. Each calf was given a score of $1=$ approaches individual with no hesitation; $2=$ hesitant but shows curiosity and slow approach; $3=$ sustains distance from individual; or $4=$ avoids individual and shows fear. This approach scoring system is a modified version of the method described by Lensink et al. (2003) and was used by Cobb et al. (2014). The second behavior scoring test measured the response of each calf when they were placed in an isolated cage when they were weighed (scale). The cage surrounding the scale was $0.7 \times 1.5 \mathrm{~m}$. The calf was placed in the cage and was free to move. Calves within the pen did not have visual or auditory contact with any other calves. This was a modified procedure of that described by Friend (1991). Briefly, each calf was objectively scored as 1 = displays frequent movement, turning, kicking, and excessive play on the scale; 2 = displays curiosity, frequent movement, play, and some turning on the scale; 3 $=$ displays light pacing and moving on the scale; and 4 $=$ displays little or no movement, curiosity, or play on the scale. Cobb et al. (2014) also used this scale-scoring system.

\section{Statistical Analyses}

All repeated, continuous data were analyzed by restricted maximum-likelihood ANOVA using the MIXED procedure of SAS (v.9.2, SAS Institute Inc., Cary, NC). The covariance structures of compound symmetry and auto-regressive(1) were tested for the within-subject measurements and the structure with the best fit was determined from the Bayesian Information Criteria. The model included the fixed effects of treatment, time, and treatment $\times$ time. The random effect was calf nested within treatment $\times$ pen. A Kenward-Roger correction was applied to the denominator degrees of freedom to obtain appropriate standard errors and $F$ statistics for each model. No enrollment group $\times$ treatment $\times$ time or enrollment group $\times$ treatment effect was detected, so enrollment group was not included in the final statistical model. Prior to statistical analyses, repeated data were tested for normality by evaluating the Shapiro-Wilk statistic using the UNIVARIATE procedure of SAS. Pairwise differences were performed at each time interval with a Duncan's adjustment to control the family-wise Type I error. Categorical data, such as behavior scores, health outcomes, and mortality, were analyzed with a chi-squared test of homogeneity using the FREQ procedure of SAS to determine whether differences in distributions of the frequency among treatments were present. The repeated, categorical data were analyzed separately for each time point. Differences of $P \leq 0.05$ were considered significant and $0.05<P<0.10$ was considered a tendency. 


\section{RESULTS}

\section{Performance}

No treatment or treatment $\times$ time effect was observed on calf height and length throughout the study (data not shown). Calf starter intake for G1, G2, and G3 calves were not different during the neonatal period, but both $\mathrm{G} 2$ and $\mathrm{G} 3$ calves had elevated $(P \leq$ $0.05)$ calf starter intake after weaning, on wk 8,9 , and 11 (Figure 1). The increased intake did not result in greater ADG throughout the first $90 \mathrm{~d}$ of life $(P>0.10$; Figure 2). Similarly, when calves were commingled into larger groups at d 90, no differences in ADG among treatments $(P>0.10$; Figure 3$)$ was observed.

\section{Calf Health and Leukocyte Responses}

The individual calf health data for the first $90 \mathrm{~d}$ of the study are reported in Table 2. One calf in each of the previous housing treatments was treated for respiratory disease during the grower phase from d 90 to 161. No differences were observed in the incidence of scours among housing treatments. Further, no treatment differences were noted in the median day of the study that the scours started or the duration of the scouring event. Additionally, no treatment differences in the incidence of severely ill calves in the first $2 \mathrm{wk}$ of life were present; however, a tendency $(P=0.08)$ for a treatment difference in the incidences of respiratory disease in the first $90 \mathrm{~d}$ of life was observed. The G1 calves had a reduced incidence of respiratory disease.

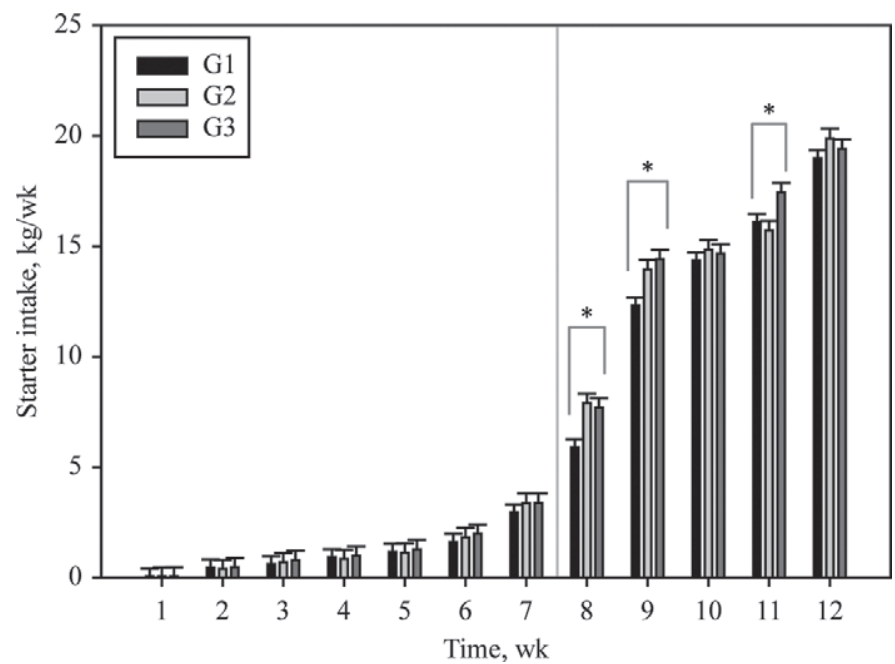

Figure 1. Calf starter intakes of individually housed calves (G1) or calves that were housed in groups of 2 (G2) or 3 (G3) during the first $90 \mathrm{~d}$ of life. The vertical line indicates when weaning was initiated. A treatment $\times$ time $(P \leq 0.05)$ effect was observed, with the sliced treatment effects denoted as ${ }^{*} P \leq 0.05$. Data reported as LSM \pm SEM.

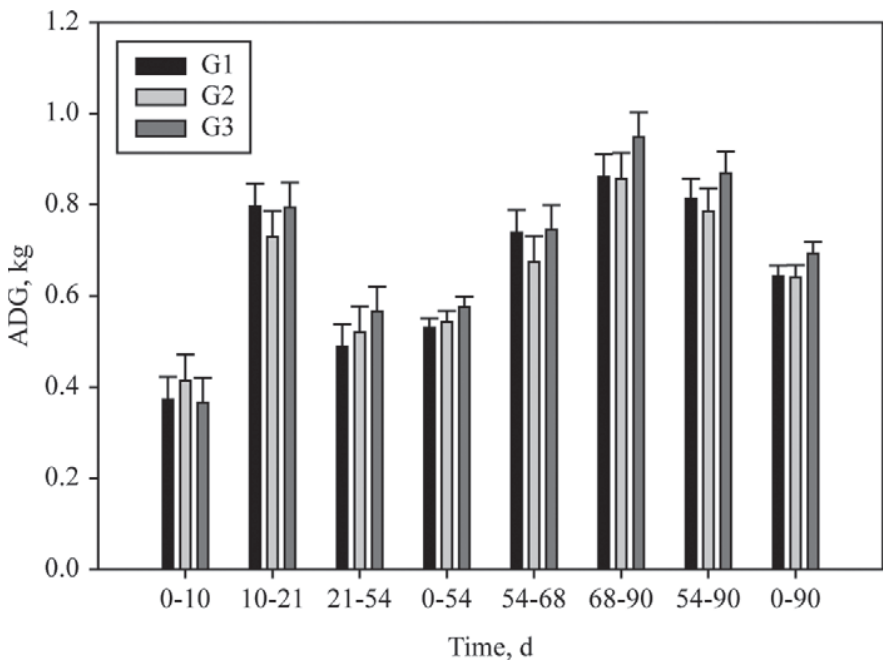

Figure 2. Average daily gains of individually housed calves (G1) or calves that were housed in groups of 2 (G2) or 3 (G3) during the first $90 \mathrm{~d}$ of life. No treatment $\times$ time or treatment effects $(P>0.10)$ were observed. Data reported as LSM \pm SEM.

Finally, no treatment difference was seen in mortality observed during the study $(P=0.20)$.

All immunological and metabolic data for the neonatal, weaning, and commingling periods are reported in Table 3. During the neonatal period, a treatment $\times$ time effect was noted on the percentage of neutrophils producing an $\mathrm{OB}(P \leq 0.05)$; however, no pairwise comparisons at any sampling time were significant $(P>$ 0.10). Throughout the commingling period, G3 calves

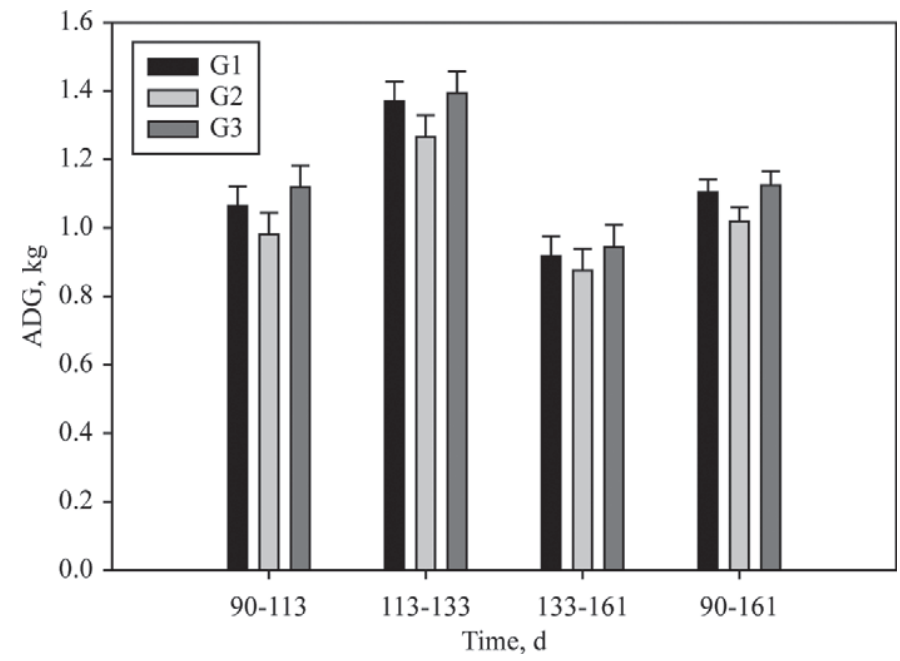

Figure 3. Average daily gains of calves that were previously housed individually (G1) or calves that were housed in groups of 2 (G2) or 3 (G3) during the first $90 \mathrm{~d}$ of life. Calves were completely randomized to larger groups of 5 calves per treatment in outdoor pens for $70 \mathrm{~d}$. No treatment $\times$ time or treatment effects $(P>0.10)$ were observed. Data reported as LSM $\pm \mathrm{SEM}$. 
Table 2. The health of calves during the first $90 \mathrm{~d}$ of the experiment ${ }^{1}$

\begin{tabular}{lrrrr}
\hline & \multicolumn{3}{c}{ Treatment } & \\
\cline { 2 - 4 } Item & G1 & G2 & G3 & $P$-value \\
\hline Scour $^{2}$ incidence, \% & 66 & 44 & 57 & $<0.29$ \\
Scour initiated, d $_{\text {Scour duration, d }}$ & 5 & 6 & 6 & $<0.90$ \\
Severely ill, ${ }^{3} \%$ & 3 & 3 & 3 & $<0.98$ \\
Respiratory disease, ${ }^{4} \%$ & 30 & 37 & 17 & $<0.24$ \\
Mortality, \% & 10 & 23 & 34 & $<0.08$ \\
& 7 & 23 & 17 & $<0.20$ \\
\hline
\end{tabular}

${ }^{1}$ Calves were either individually housed calves (G1) or housed in groups of 2 (G2) or 3 (G3).

${ }^{2}$ Scours were classified as having 2 consecutive days with a fecal score $\geq 3$. Fecal scores were recorded before each feeding according to Larson et al. (1977). Data are reported as incidence (\% of calves), the median days calves began to scour, and the median duration of the scours.

${ }^{3}$ Severely ill calves were less than 2 wk old and had no suckle reflex with a decreased response to external stimuli. They were treated with Resflor Gold (Merck Animal Health, Summit, NJ) and given oral electrolytes in $2 \mathrm{~L}$ of milk replacer using an esophageal feeder.

${ }^{4}$ Respiratory disease was classified based on nasal discharge or cough with $\geq 39.5^{\circ} \mathrm{C}$ rectal temperature. Calves were treated with Resflor Gold (Merck Animal Health).

had greater $(P \leq 0.05)$ plasma glucose concentrations. No other treatment $\times$ time or treatment differences were seen in the other leukocyte responses or blood metabolites during either the neonatal, weaning, or commingling periods.

\section{Behavior}

Frequency distributions of approach scores during the neonatal period for G1 and G2 calves were different at d $10(P \leq 0.05$, Figure 4$)$, and G1 distribution was different from G2 and G3 at d $21(P \leq 0.05)$. Immediately before initiating weaning at d 46, G1 distribution was different from G2 and G3 $(P \leq 0.05)$; however, no treatment differences were observed at either d 48 or 54. Differences in the frequency distributions of approach scores were apparent again immediately before commingling on d 90, whereas G1 score frequencies were different $(P \leq 0.05)$ from that of $\mathrm{G} 2$ and G3. Generally, a greater percentage of G1 calves approached the human observer than either the G2 or G3 calves.

Frequency distributions of scale scores for calves were different during the neonatal period; whereas, at d 10, the G1 distributions were different from G3 $(P \leq 0.05$, Figure 5$)$, and on d 21 each treatment was different from the other 2 treatments $(P \leq 0.05)$. At the end of weaning on d 54, G2 scale score frequencies were different from G3 $(P \leq 0.05)$. Individually housed calves scored differently from G2 calves $(P \leq$ $0.05)$ and tended $(P<0.10)$ to be different from G3 calves at $\mathrm{d} 68$. Immediately before commingling at $\mathrm{d}$ 90, G3 scale scoring distribution was different from

Table 3. Leukocyte responses and plasma metabolites of individually housed calves (G1) or calves that were housed in groups of 2 (G2) or 3 (G3)

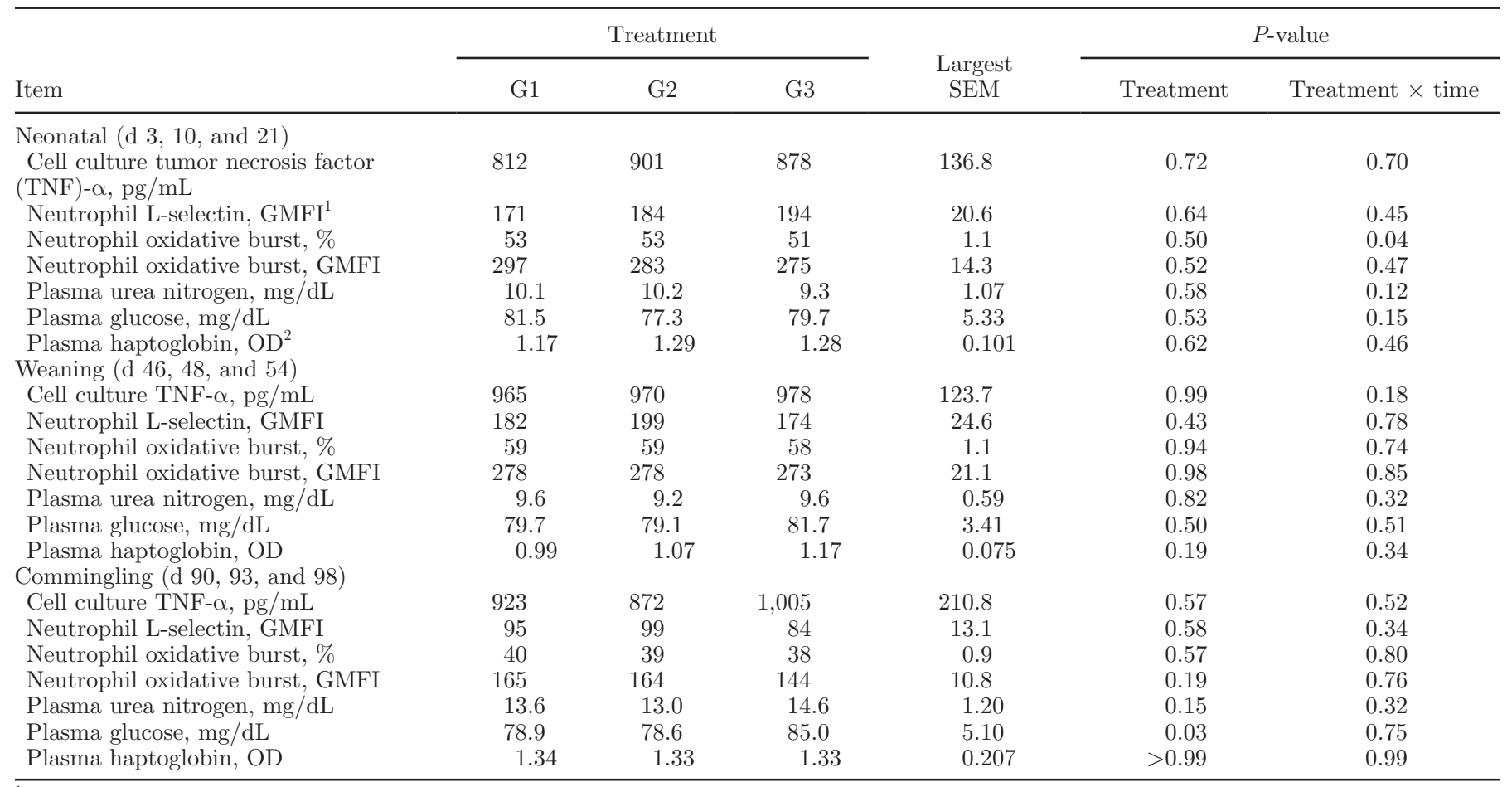

${ }^{1} \mathrm{GMFI}=$ geometric mean fluorescence intensity.

${ }^{2} \mathrm{OD}=$ optical density. 


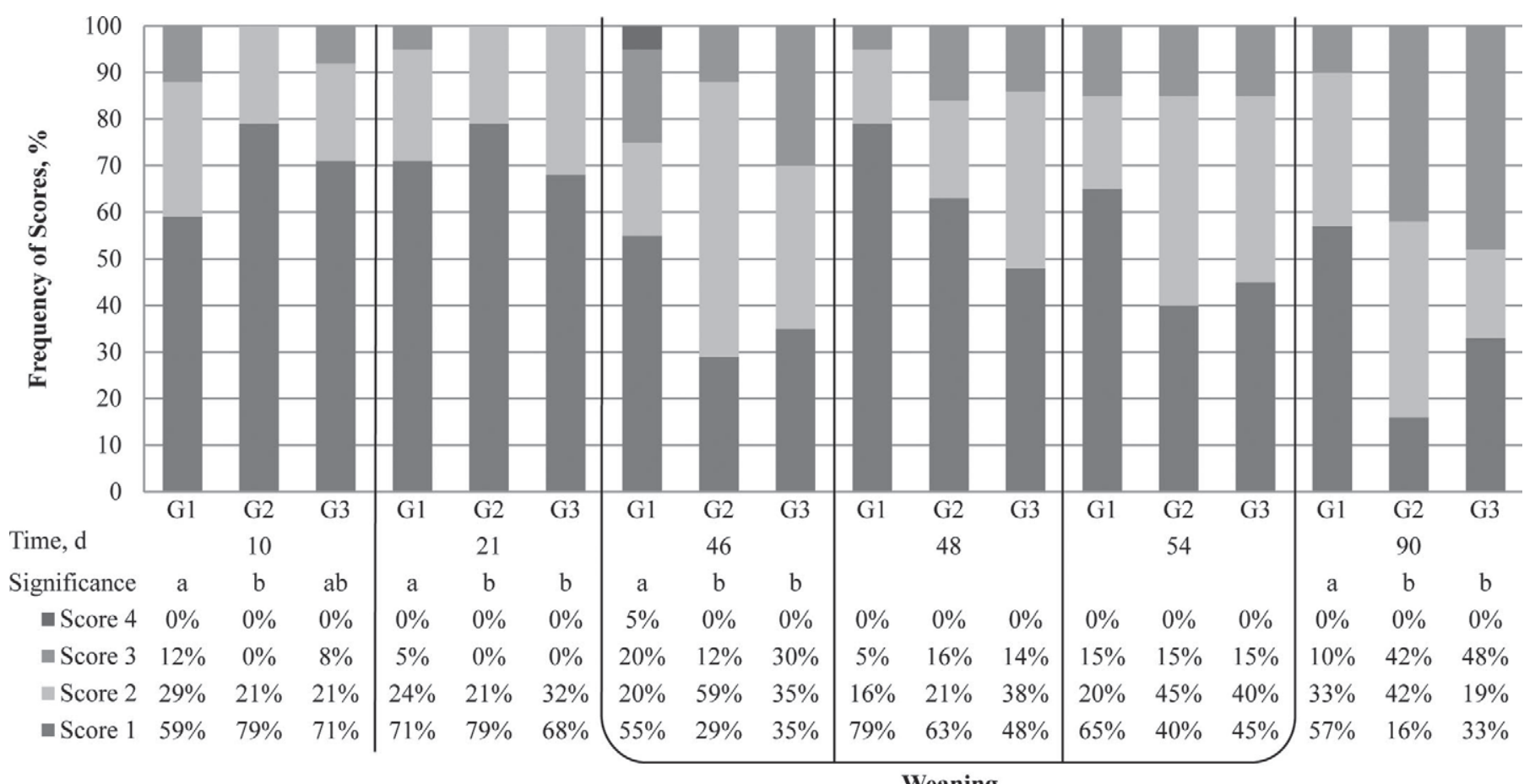

Weaning

Figure 4. Frequency of approach scores among individually housed calves (G1) or calves that were housed in groups of 2 (G2) or 3 (G3) during the first $90 \mathrm{~d}$ of life. Different letters for significance symbolize treatment differences of $P \leq 0.05$. The approach scores were given as (1) approaches individual with no hesitation; (2) hesitant but shows curiosity and slow approach; (3) sustains distance from individual; and (4) avoids individual and shows fear.

G1 and G2 calves $(P \leq 0.05)$. Generally, a greater percentage of G1 calves showed more exploratory behavior when placed in an isolated cage than either G2 or G3 calves.

\section{DISCUSSION}

\section{Performance}

Group-housed dairy calves often consume more calf starter than calves that are in individual pens or hutches (Warnick et al., 1977; De Paula Vieira et al., 2010; Cobb et al., 2014). It was suggested that the increased calf starter intake among group-housed calves is due to either learned behaviors or competition among penmates (Babu et al., 2004). The current data support that group-housing increases calf starter intake during the immediate postweaning period (i.e., wk 8, 9, and 11); furthermore, it did not matter if 2 or 3 calves were present per pen. The increased calf starter intake among group-housed calves did not occur until after weaning in the current study. All calves in the study were fed a high plane of milk replacer, which consistently reduces preweaned calf starter intake (Osorio et al., 2012; Ballou et al., 2013; Obeidat et al., 2013). Therefore, the lower calf starter intake among all calves may have masked any treatment effect on calf starter intake during the preweaning period.

The greater calf starter intake among the grouphoused calves did not translate into an increased ADG during the postweaning period, which contrasts with the data reported by De Paula Vieira et al. (2010) and Cobb et al. (2014), in which both observed an increased ADG along with the increased calf starter intake. The lack of an effect in ADG could be due to a mild increase in activity or decrease in health among the group-housed calves during the weeks immediately following weaning. Duve and Jensen (2012) reported that calves housed in pairs performed more social behaviors than calves housed individually. In addition, a tendency was observed in the current study for individually housed calves to be treated less for respiratory disease during the first $90 \mathrm{~d}$ of the study. Group-housed calves in the current study did not have improved ADG when they were commingled in a pen with 4 other random calves 1 mo after weaning when compared with the individually housed calves. The current data contrast those of De Paula Vieira et al. (2010), who reported that individually housed calves that were introduced to larger group pens postweaning took approximately $50 \mathrm{~h}$ to begin feeding compared with $9 \mathrm{~h}$ for calves raised in pairs. In agreement with De Paula Vieira et al. (2010), Cobb et al. (2014) observed 


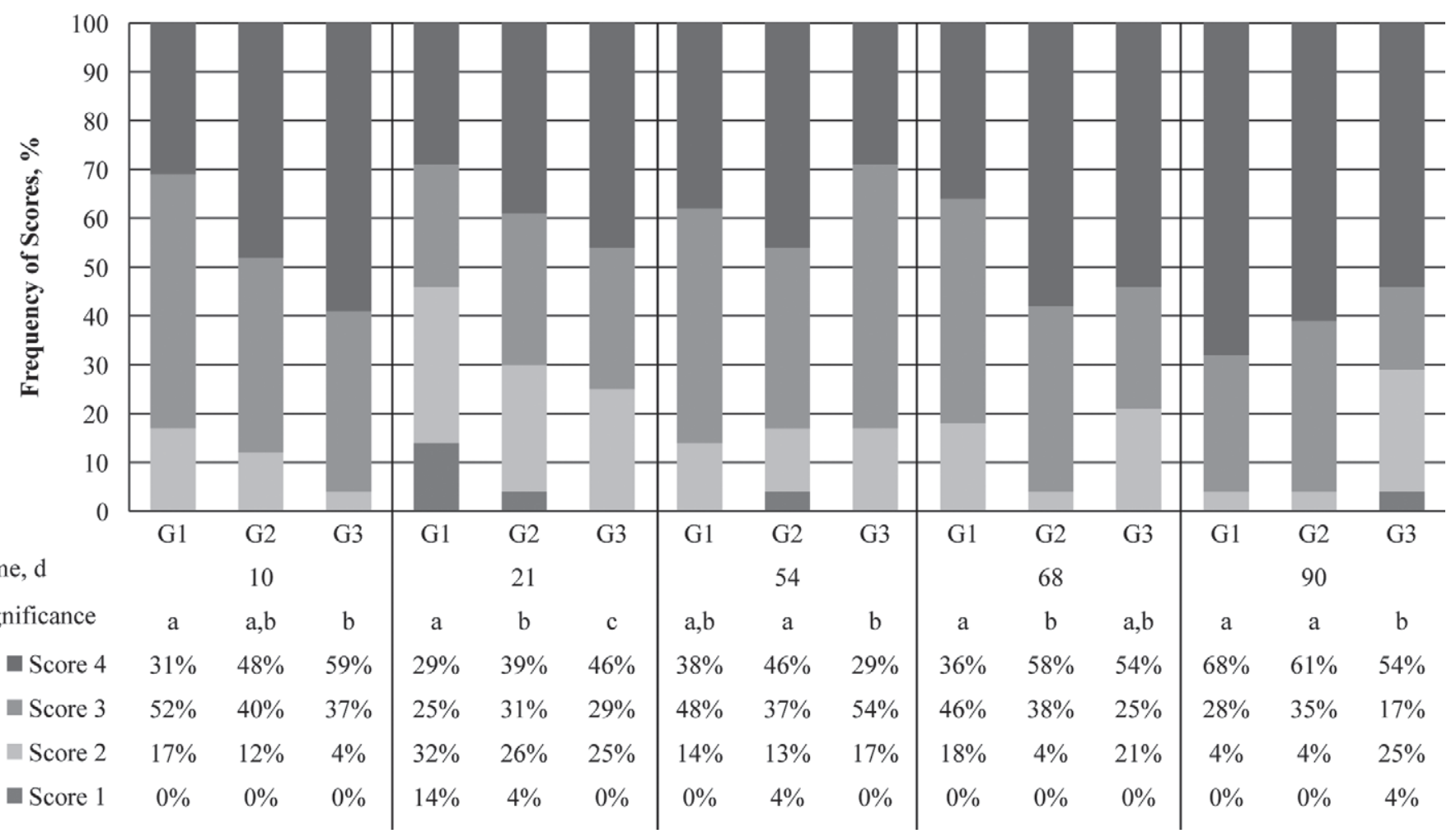

Figure 5. Frequency of scale scores among individually housed calves (G1) or calves that were housed in groups of 2 (G2) or 3 (G3) during the first $90 \mathrm{~d}$ of life. Different letters for significance indicate treatment differences of $P \leq 0.05$. The scale scores were given as (1) displays frequent movement, turning, kicking, and excessive play on the scale; (2) displays curiosity, frequent movement, play, and some turning on the scale; (3) displays light pacing and moving on the scale; and (4) displays little or no movement, curiosity, or play on the scale.

that calves that were group-housed earlier in life tended to have greater average daily gains when they were commingled into larger groups 1 mo after weaning.

\section{Calf Health and Leukocyte Responses}

Hutches are common housing for preweaned dairy calves in the United States; however, in areas where drastic changes in temperature or cold climates are common, many calves are raised in various types of barns. Enzootic pneumonia is commonly reported in poorly ventilated barns. The current study assessed indoor calf housing with poor ventilation and drainage, which resulted in high incidences of both gastrointestinal and respiratory diseases that exceed the most recent producer-perceived national averages of 23.9 and $18.3 \%$ estimated by NAHMS (2007), respectively. The average incidences across treatments for gastrointestinal and respiratory diseases in the current study were 55.7 and $22.3 \%$, respectively.

Calves are extremely susceptible to disease during the preweaning period; therefore, one of the most common strategies to improve health is to reduce horizontal transmission of diseases. Individually housing calves, without physical contact with other calves, can be effective in reducing horizontal transmission of diseases. In the present study, the individually housed calves tended to have a lower incidence of respiratory disease than calves group-housed in either 2 or 3 calves per pen. Lago et al. (2006) reported that indoor calf barns that had a solid barrier to prevent nose-to-nose contact between calves reduced the incidence of respiratory disease, which is in agreement with the present data. Calves in the current study had physical barriers that prevented physical contact between calves in adjacent pens; thereby potentially reducing horizontal transmission of respiratory pathogens. Numerous data agree with current data and reported an increased morbidity and mortality among group-housed calves compared with individually housed calves (Fourichon et al., 1997; Losinger and Heinrichs, 1997; Gulliksen et al., 2009), whereas others have reported either no differences or improvements in the health of group-housed calves (Chua et al., 2002; Hanninen et al., 2003; Cobb et al., 2014). The health of a calf is dependent on many variables; therefore, it is not surprising that data does not agree regarding the influence of group housing on the health of calves. Perez et al. (1990) performed an obser- 
vational epidemiological study of 63 commercial Dutch dairy farms with morbidity and mortality data from 1,037 calves and reported that group housing calves was one of the many significant variables that increased the odds for mortality. Therefore, taken together, calves can be raised in groups without increasing either morbidity or mortality, but this is likely dependent on many other factors, including the environment in which the calves are raised and other management decisions. The data in the present study indicate that group housing calves in indoor pens with poor ventilation and drainage increases the risk of developing respiratory disease.

No differences were observed in leukocyte responses among the different housing treatments at any time during the current study. This contrasts with the data reported by Cobb et al. (2014), where they observed elevated neutrophil surface L-selectin protein concentrations and neutrophil oxidative burst capacities among group-housed calves during the preweaned and weaning periods when compared with individually housed calves. The elevated neutrophil responses were no longer apparent after weaning in the study by Cobb et al. (2014). A reason for the discrepancy in the data from Cobb et al. (2014) and the current study could be the different environmental conditions. Calves in the previous study were housed in outdoor hutches and reported lower incidences of morbidity and mortality. Therefore, the poorer environment in which the calves were raised, greater humidity, moist bedding, and higher concentration of noxious gases in the current study may have homogenized the leukocyte responses.

Many stressors, including weaning, castration, amputation dehorning, and transportation have been reported to suppress neutrophil responses of calves (Burton et al., 1995). Hulbert et al. (2011) reported that more abrupt weaning of calves fed lower planes of milk replacer suppresses neutrophil responses of dairy calves. Chua et al. (2002) reported that calves raised in pairs during the preweaning period had improved ADG during weaning when compared with individually housed calves. The authors hypothesized that the improved ADG by group-housed calves was likely due to the calves' ability to better cope with stress (Chua et al., 2002). In the present study, no differences in the leukocyte responses of calves among the different housing treatments were observed during either weaning or commingling. This agrees with the lack of an effect on ADG during either weaning or commingling. Neutrophil responses in the present study were not suppressed during either weaning or commingling; therefore, the lack of a treatment effect may have been masked by the fact the calves were able to cope with both of those stressors. In fact, calves in the present study were fed a higher plane of milk replacer nutrition and weaned using a step-down approach, whereas Hulbert et al. (2011) more abruptly weaned calves that were fed a lower plane of milk replacer.

\section{Behavior}

During the neonatal period, all calves exhibited behaviors demonstrating that they acclimated to their environment and associated humans with milk during milk feedings, as most calves were willing to approach the observer during behavior assessments. However, the approach score immediately before weaning indicated that G1 calves were more comfortable with humans than either G2 or G3. This is in agreement with Cobb et al. (2014), who observed that individually housed calves in outdoor hutches were more likely to approach a human observer than calves that were housed in groups of 3 in outdoor hutches. During weaning, more calves in all housing treatments approached the human observer, which was also reported by Cobb et al. (2014). This is likely due to the restriction of milk and that calves associated milk feeding with humans, independent of housing treatment. However, by d 90, the G2 and G3 calves were less approachable again and depended on calf-to-calf interactions more than calf-to-human interactions. Supporting the current findings, Gyorkos et al. (1999) observed that group-housed calves were more difficult to handle, had more interactions with other calves, and became easier to handle with more human contact.

Friend (1991) discussed the fact that more comfortable calves interact with new surroundings, whereas more stressed and uncomfortable calves will display signs of helplessness. Greater percentages of G2 and G3 calves at d 21 displayed little or no movement on the scale when compared with the G1 calves. In agreement, Cobb et al. (2014) observed that group-housed calves displayed less movement on the scale than individually housed calves, which was consistently observed throughout the 90-d study and suggests that grouphoused calves rely more on calf-to-calf interactions. The data in the present study were not as consistent throughout the study duration as with that observed by Cobb et al. (2014). The poor ventilation and drainage of the barn facility required more labor and human exposure to calves to remove soiled bedding and add new dry bedding. This frequent human interaction may have resulted in group-housed calves that became more comfortable with the sight, sound, and movement of humans. In fact, the group-housed calves in the current study exhibited a higher frequency of exploratory behaviors in the isolated scale pen than the group-housed calves in the study by Cobb et al. (2014). In support, Gyorkos et al. (1999) and Lensink et al. (2001) reported 
that group-housed calves could be more easily handled if provided with human interaction. More research is needed to determine how the dependency on both calf-to-calf and calf-to-human interactions influences a calf's well-being and response to common stressors early in life.

\section{CONCLUSIONS}

The benefits and detriments of group housing depend on many environmental and management factors. Group housing calves in indoor pens with poor natural ventilation and drainage tended to increase the incidence of respiratory disease. Therefore, calves that are raised in a poorly ventilated and drained environment will likely benefit from individual housing. Furthermore, the behavior of group-housed calves indicated that calves relied more on calf-to-calf interactions than calf-to-human interactions, but the effect was lessened with increased human contact.

\section{ACKNOWLEDGMENTS}

Authors acknowledge the milk replacer donations and feeding recommendations made by Land O'Lakes Animal Milk Products Co. (Shoreview, MN). The authors thank Devin Hanson and Logan Jackson with Texas Tech University for their assistance with the calf husbandry.

\section{REFERENCES}

AOAC International. 1995. Official Methods of Analysis. 16th ed. AOAC International, Arlington, VA.

Babu, L. K., H. N. Pandey, and A. Sahoo. 2004. Effect of individual versus group rearing on ethological and physiological responses of crossbred calves. Appl. Anim. Behav. Sci. 87:177-191.

Ballou, M. A., C. J. Cobb, T. J. Earleywine, and B. S. Obeidat. 2013 Interaction of breed and plane of milk replacer nutrition on the performance of pre- and post-weaned dairy calves. Prof. Anim. Sci. 29:116-123.

Burton, J. L., M. E. Kehrli Jr., S. Kapil, and R. L. Horst. 1995 Regulation of L-selectin and CD18 on bovine neutrophils by glucocorticoids: Effects of cortisol and dexamethasone. J. Leukoc. Biol. 57:317-325.

Chua, B., E. Coenen, J. van Delen, and D.M. Weary. 2002. Effects of pair versus individual housing on the behavior and performance on dairy calves. J. Dairy Sci. 85:360-364.

Cobb, C. J., B. S. Obeidat, M. D. Sellers, A. R. Pepper-Yowell, D. L. Hanson, and M. A. Ballou. 2014. Improved performance and heightened neutrophil responses during the neonatal and weaning periods among outdoor group-housed Holstein calves. J. Dairy Sci. 97:930-939.

Council of the European Union. 1997. Council Directive 97/2/EEC of 20 January 1997 amending Directive 91/629/EEC laying down minimum standards for the protection of calves. Office Journal of the European Communities, Brussels, Belgium.

De Paula Vieira, A., M. A. G. von Keyserlingk, and D. M. Weary. 2010. Effects of pair versus single housing on performance and behavior of dairy calves before and after weaning from milk. J. Dairy Sci. 93:3079-3085.
Duve, L. R., and M. B. Jensen. 2012. Social behavior of young dairy calves housed with limited or full social contact with a peer. J. Dairy Sci. 95:5936-5945.

Fourichon, C., F. Beaudeau, and H. Seegers. 1997. Critical points related to housing and management in control programmes for calf morbidity and mortality in French dairy herds. Pages $32-35$ in Ninth International Congress on Animal Hygiene. ICAH, Helskinki, Finland.

Friend, T. H. 1991. Behavioral aspects of stress. J. Dairy Sci. 74:292303.

Gulliksen, S. M., K. I. Lie, T. Løken, and O. Østeras. 2009. Calf mortality in Norwegian dairy herds. J. Dairy Sci. 92:2782-2795.

Gyorkos, I., M. Mézes, E. Szücs, K. Kovács, G. Borka, G. Gábor, and J. Volgyi-Csíl. 1999. Behavioural development of Holstein-Friesian cows and calves. Acta Agronomica Hungarica. 41:39-52.

Hanninen, L., H. Hepola, J. Rushen, A. M. de Passillé, P. Pursioainen, and V. M. Tuure. 2003. Resting behavior, growth and diarrhea incidence rate of young dairy calves housed individually or in groups in warm or cold buildings. Acta Agric Scand. Anim. Sci. 53:21-28.

Hulbert, L. E., C. J. Cobb, J. A. Carroll, and M. A. Ballou. 2011. The effects of weaning on innate immune responses of Holstein calves. J. Dairy Sci. 94:2545-2556.

Lago, A., S. M. McGuirk, T. B. Bennett, N. B. Cook, and K. V. Nordlund. 2006. Calf respiratory disease and pen microenvironments in naturally ventilated calf barns in winter. J. Dairy Sci. 89:4014-4025.

Larson, L. L., F. G. Owen, J. L. Albright, R. D. Appleman, R. C. Lamb, and L. D. Muller. 1977. Guidelines toward more uniformity in measuring and reporting calf experimental data. J. Dairy Sci. 60:989-991.

Lensink, B. J., S. Raussi, X. Boivin, M. Pyykkönen, and I. Veissier. 2001. Reactions of calves to handling depend on housing condition and previous experience with humans. Appl. Anim. Behav. Sci. 70:187-199.

Lensink, B. J., C. G. van Reenen, B. Engel, T. B. Rodenburg, and I. Veissier. 2003. Repeatability and reliability of an approach test to determine responsiveness to humans: A brief report. Appl. Anim. Behav. Sci. 83:325-330.

Losinger, W. C., and A. J. Heinrichs. 1997. Management practices associated with high mortality among preweaned dairy heifers. J. Dairy Res. 64:1-11.

NAHMS (National Animal Health Monitoring System). 2007. Dairy 2007: Heifer calf health and management practices on U.S. dairy operations. USDA Animal and Plant Health Inspection Service Veterinary Service, Fort Collins, CO.

NAHMS (National Animal Health Monitoring System). 2011. Dairy Heifer Raiser, 2011. USDA Animal and Plant Health Inspection Service, Fort Collins, CO.

Obeidat, B. S., C. J. Cobb, M. D. Sellers, A. R. Pepper-Yowell, T. J. Earleywine, and M. A. Ballou. 2013. Plane of nutrition during the pre-weaning period but not the grower phase influences the neutrophil activity of Holstein calves. J. Dairy Sci. 96:7155-7166.

Office of the Attorney General. 2008. Standards for Confining Farm Animals (The California Prevention of Farm Animal Cruelty Act). Initiative 2007-08-09, retrieved on 2008-09-24. Attorney General's Office, California Department of Justice, Sacramento, CA.

Osorio, J. S., R. L. Wallace, D. J. Tomlinson, T. J. Earleywine, M. T. Socha, and J. K. Drackley. 2012. Effects of source of trace minerals and plane of nutrition on growth and health of transported neonatal dairy calves. J. Dairy Sci. 95:5831-5844.

Perez, E. J., P. T. M. Noordhuizen, L. A. Van Wuijkhuise, and E. N. Stassen. 1990. Management factors related to calf morbidity and mortality rates. Livest. Prod. Sci. 25:79-93.

Sellers, M. D., L. E. Hulbert, and M. A. Ballou. 2013. Technical note: Determination of pre-analysis storage temperature and time allowances for ex vivo innate immune responses. J. Dairy Sci. 96:384389.

Vasseur, E., F. Borderas, R. I. Cue, D. Lefebvre, D. Pellerin, J. Rushen, K. M. Wade, and A. M. de Passillé. 2010. A survey of dairy 
calf management practices in Canada that affect animal welfare. J. Dairy Sci. 93:1307-1315.

Warnick, V. D., C. W. Arave, and C. H. Mickelsen. 1977. Effects of group, individual and isolated rearing of calves on weight gain and behavior. J. Dairy Sci. 60:947-953.
Woolums, A. R., T. R. Ames, and J. C. Baker. 2009. The bronchopneumonias (respiratory disease complex of cattle, sheep, and goats). Pages 602-643 in Large Animal Internal Medicine. 4th ed. B. P. Smith, ed. Mosby, Elsevier, St. Louis, MO. 